\title{
Tetragonal superlattice of elongated rhombic dodecadedra for sensitive SERS determination of pesticide residues in fruit
}

\author{
Shuang Lin, Xinxin Li, Guoqiang Fang, Haiyan Zhao, Li Wang," Bin Dong* \\ Key Laboratory of New Energy and Rare Earth Resource Utilization of State Ethnic Affairs Commission, Key Laboratory of \\ Photosensitive Materials\&Devices of Liaoning Province, School of Physics and Materials Engineering, Dalian Minzu University, \\ Dalian 116600, China.
}

\section{EXPERIMENTAL SECTION}

\section{Materials}

Cetyltrimethylammonium bromide (CTAB), cetyltrimethylammonium chloride (CTAC, 25\% w/w) and polyvinyl pyrrolidone (PVP) were purchased from Sigma-Aldrich, sodium oleate (NaOL) and 4-mercapto benzoic acid (4-MBA) were purchased from TCI America, sodium borohydride $\left(\mathrm{NaBH}_{4}\right)$ and ascorbic acid $(\mathrm{AA})$ were purchased from Acros Organics, silver nitrate $(\mathrm{AgNO})$ and chloroauric acid $\left(\mathrm{HAuCl}_{4}\right)$ were purchased from Sinopharm Chemical Reagent Co. Ltd., cetylpyridinium chloride monohydrate (CPC) was purchased from Shanghai Sangon Company, crystal violet (CV) was purchased from Adamas Reagent Co., Ltd., quartz slides were purchased from Nantong Ruisen Optical Technology Co., Ltd. Ultrapure water was obtained from a Milli-Q system for all experiments.

\section{Synthesis of gold nanorod seeds}

Gold nanorod seeds were synthesized according to the method proposed by Murray et al. ${ }^{1}$ At first, $3 \mathrm{~nm}$ Au nanoclusters were prepared and then CTAB $(0.9 \mathrm{~g})$ and $\mathrm{NaOL}(0.1543 \mathrm{~g})$ was dissolved together in $25 \mathrm{~mL}$ of water. Then $\mathrm{AgNO}_{3}(4 \mathrm{mM}, 1.8 \mathrm{~mL}), \mathrm{HAuCl}_{4}(1 \mathrm{mM}$, $25 \mathrm{~mL}), \mathrm{HCl}(12.1 \mathrm{M}, 0.21 \mathrm{~mL})$ and AA $(64 \mathrm{mM}, 125 \mu \mathrm{L})$ were added to the mixed solution one after another and gently stirred. Finally, $3 \mathrm{~nm}$ Au seed $(4 \mathrm{~mL})$ were injected into the growth solution. The mixture was stirred for $30 \mathrm{~s}$ and left undisturbed at $30^{\circ} \mathrm{C}$ for $12 \mathrm{~h}$. The product was centrifuged and dispersed into water $(5 \mathrm{~mL})$.

\section{Synthesis of gold elongated rhombic dodecadedra}

Gold elongated rhombic dodecadedra was synthesized according to the method by Mirkin et al. ${ }^{2}$ The seed needs to be centrifuged and re-dispersed into CPC solution. CPC solution $(40 \mathrm{~mL}, 100 \mathrm{mM})$ was mixed with $\mathrm{HCl}(2 \mathrm{~mL}, 1 \mathrm{mM}), \mathrm{HAuCl}_{4}$ solution $(800 \mu \mathrm{L}, 25 \mathrm{mM})$, $\mathrm{AgNO}_{3}$ solution $(104 \mu \mathrm{L}, 10 \mathrm{mM})$ and AA solution $(240 \mu \mathrm{L}, 100 \mathrm{mM})$ at $30^{\circ} \mathrm{C}$ with gently stir. And Au seed solution concentrated by 10 times $(5 \mathrm{mM}, 130 \mu \mathrm{L}, 200 \mu \mathrm{L}, 400 \mu \mathrm{L})$ was added to the mixed solution and reacted for $5 \mathrm{~h}$. Finally, the product was centrifuged and dispersed into CTAB solution.

\section{Synthesis of gold nanorods}

The seed needs to be centrifuged and re-dispersed into CTAB solution. Then, CTAB (0.9 g) and NaOL (0.1543 g) was dissolved together in $25 \mathrm{~mL}$ of water. Then $\mathrm{AgNO}_{3}(4 \mathrm{mM}, 1.8 \mathrm{~mL}), \mathrm{HAuCl}_{4}(1 \mathrm{mM}, 25 \mathrm{~mL}), \mathrm{HCl}(12.1 \mathrm{M}, 0.21 \mathrm{~mL})$ and AA $(64 \mathrm{mM}, 125 \mu \mathrm{L})$ were added to the mixed solution one after another and gently stirred. Finally, Au seed $(250 \mu \mathrm{L}, 5 \mathrm{mM})$ were injected into the growth solution. The mixture was stirred for $30 \mathrm{~s}$ and left undisturbed at $30^{\circ} \mathrm{C}$ for $12 \mathrm{~h}$. Finally, the product was dispersed into CTAB solution after centrifugation.

\section{Assembly of standing gold elongated rhombic dodecadedra superstructure}

Typically, the nanoparticles were centrifuged twice and re-dispersed into CTAC or CTAB solution with various concentrations ( $0.2 \mathrm{mM}$, $0.5 \mathrm{mM}, 1 \mathrm{mM}$ and $2 \mathrm{mM}$ ). Si wafers require simple pretreatment by soaking and cleaning with nitrohydrochloric acid firstly. Then $\mathrm{Si}$ wafers was wiped with a cotton swab dipped in ethanol, and dried naturally before use. Subsequently, a certain amount of gold elongated rhombic dodecadedra colloid was dropped on Si wafers placed in a culture dish. The culture dish was sealed by sealing film containing some water to build a closed assembly environment with constant humidity and temperature. The assembly process can last at least $24 \mathrm{~h}$.

\section{Liquid/liquid self-assembly technique for random gold elongated rhombic dodecadedra superstructure}

The elongated rhombic dodecadedra was also assembled into a random arrangement without periodicity by the liquid/liquid self-assembly technique referring to our previous work. ${ }^{3}$ In brief, the nanoparticles were centrifuged twice and re-dispersed into ethanol 
solution. Then a certain amount of water and $\mathrm{CH}_{2} \mathrm{Cl}_{2}$ were added to form a water-oil interface. Then the elongated rhombic dodecadedra of $100 \mu \mathrm{L}$ were added. After vigorous shocking, a small amount of $\mathrm{n}$-hexane was added and a dense monolayer was slowly formed on the interface. Finally, the redundant $n$-hexane was removed slowly and gently by a pipette and then deposited on the Si wafer.

\section{Preparation of 4-MBA samples and pesicides spiked apple samples and grape samples}

The parathion-methyl standard solution of $100 \mathrm{~g} / \mathrm{L}$ (in methanol) was diluted with different proportions to prepare aqueous solutions of parathion-methyl with different concentrations. To prepare carbaryl standard solution, $0.201 \mathrm{~g}$ carbaryl powder was weighed and then dissolved it into $10 \mathrm{~mL}$ acetone. Aqueous solutions of carbaryl with different concentrations were prepared by diluting carbaryl standard solution with different proportions. To prepare spiked apple and grape samples, the apples and grapes were washed and peeled followed by soaking in different concentrations of pesticides and dried naturally for later use. $1 \mathrm{~g}$ of peels with different spiked concentrations and $10 \mathrm{~mL}$ of water were added in a high speed blender to break them and then the supernatant was extracted for SERS detection after centrifugation.

\section{FDTD simulation}

The FDTD calculations were performed using FDTD Solutions 8.0 software developed by Lumerical Solutions Inc. For all simulations, the dielectric function of gold was represented with the fitting from Johnson and Christy's data. And the size of the nanostructure was set according to the statistical results of the average size measured from the experimental results. For the array calculation, the gap of the nanocrystals was set to $1 \mathrm{~nm}$ and the background refractive index was set to 1 (the refractive index of air). The period boundary condition was adapted to $\mathrm{x}, \mathrm{y}$ axis direction and the perfectly matched layer (PML) boundary condition was adapted to $\mathrm{z}$ axis direction. And the light source was a plane wave source with a wavelength of $785 \mathrm{~nm}$. Meanwhile, the mesh size was set at $0.2 \mathrm{~nm}$ for the nanocrystal array.

\section{Characterization and SERS measurement}

UV-Vis spectroscopy was measured by a spectrophotometer (Model Lambda 750, Perkin Elmer, USA) and the spectra were detected between $400 \mathrm{~nm}$ and $1200 \mathrm{~nm}$. Scanning electron microscopy (SEM) images were obtained by a microscopy (model S-4800, Hitachi, Japan) with an acceleration voltage of $5.0 \mathrm{kV}$. The Transmission electron microscope (TEM) images, HRTEM image and SEAD pattern of the particles were taken by a JEM-2100 TEM instrument (JEOL, Japan). Fast Fourier Transformation (FFT) image was analyzed by Image J software. Raman spectra were collected using a portable compact laser Raman Spectrometer (BWS415-785H B\&W Tek, Inc.). The excitation wavelength of the laser is $785 \mathrm{~nm}$. The spot size of focus laser beam is $10 \mu \mathrm{m}$ in diameter. The spectrum range of the spectrometer is 175 to $2700 \mathrm{~cm}^{-1}$ with a spectral resolution of better than $3 \mathrm{~cm}^{-1}$. Boxcar averaging was used to smooth the raw spectrum and a baseline correction routine was performed to obtain the final spectrum with the background subtracted.

\section{Averaged enhancement factor (AEF)}

The normal Raman spectra of 4-MBA solid powder were collected in Figure 3(A). After that, the standing superlattice was immersed in $10^{-3} \mathrm{M} 4-\mathrm{MBA}$ aqueous solution for $2 \mathrm{~h}$ and then washed thorough to enable monolayer 4-MBA molecules adsorbed on the surface of the substrate. The SERS spectra were measured with the standing superlattice, as shown in Figure 3(B). Averaged enhancement factor was defined by the following equation: ${ }^{4}$

$$
E F=\frac{I_{\text {SERS }}}{I_{\text {bulk }}} \times \frac{M_{\text {bulk }}}{M_{a d s}}
$$

Where $I_{\text {SERS }}$ and $I_{\text {bulk }}$ are the Raman intensity of 4-MBA molecules based on the standing superlattice $\left(1076 \mathrm{~cm}^{-1}, 1586 \mathrm{~cm}^{-1}\right)$ and based on the powder $\left(1096 \mathrm{~cm}^{-1}, 1593 \mathrm{~cm}^{-1}\right)$, respectively. $M_{\text {bulk }}$ is the molecule number of the neat 4-MBA in the laser illumination volume, which can be determined by the laser spot $\left(10 \mu \mathrm{m}\right.$ in diameter) and the penetration depth $(12 \mu \mathrm{m})$ of the focused beam. $M_{a d s}$ is the number of molecules adsorbed and sampled on the standing superlattice within the laser spot, which is determined by the following equation: ${ }^{5}$

$$
M_{\text {ads }}=N_{d} A_{\text {laser }} A_{N} \rho_{b}
$$

Where $N_{d}$ is the number density of NPs, $A_{\text {laser }}$ is the area of the laser focal spot, $A_{N}$ is the NP's footprint area, and $\rho_{b}$ is the bonding density of 4-MBA molecule. ${ }^{6} N_{d}$ and $A_{N}$ can be obtained from the SEM images and analyzed by Image J software.

\section{Limit of detection (LOD)}

According to the definition of LOD by the International Union of Pure and Applied Chemistry (IUPAC), the detection limit refers to the minimum analysis signal that can be detected by a specific analysis method, and thus the lowest concentration could be obtained from the fitted curve. The expression of the minimum analysis signal $X_{L}$ was described as follows: ${ }^{7,8}$

$$
X_{L}=X_{B}+K S_{B}
$$


Where $X_{B}$ is the average value of the blank signal and the blank sample refers to the sample with the same composition of the test sample but does not contain the test component. $S_{B}$ is the standard deviation of the blank sample signal, and $K$ is related to the confidence level. IUPAC recommends $K$ to be 3 as the standard of detection limit calculation.
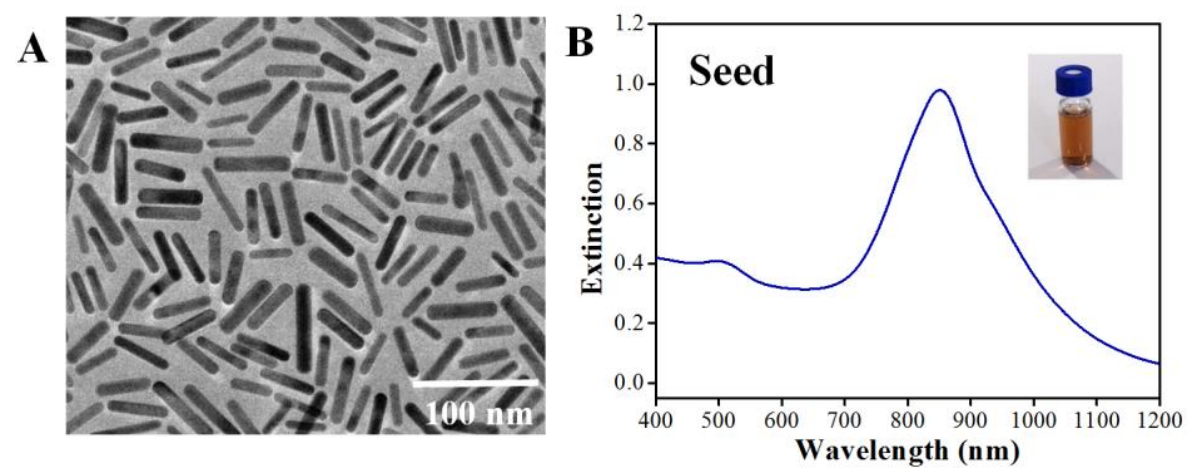

Figure S1. (A) TEM image of gold nanorod as seed; (B) UV-vis extinction spectrum of gold nanorod as seed. Inset: the picture of gold nanorod as seed.
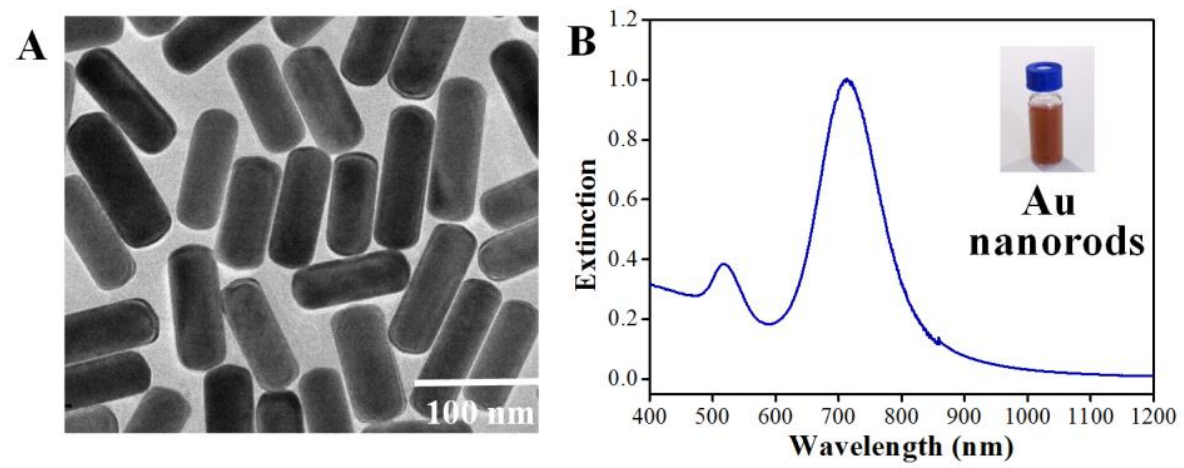

Figure S2. (A) TEM image of gold nanorod by overgrowth of seed; (B) UV-vis extinction spectrum of gold nanorod by overgrowth of seed. Inset: the picture of gold nanorod by overgrowth of seed.

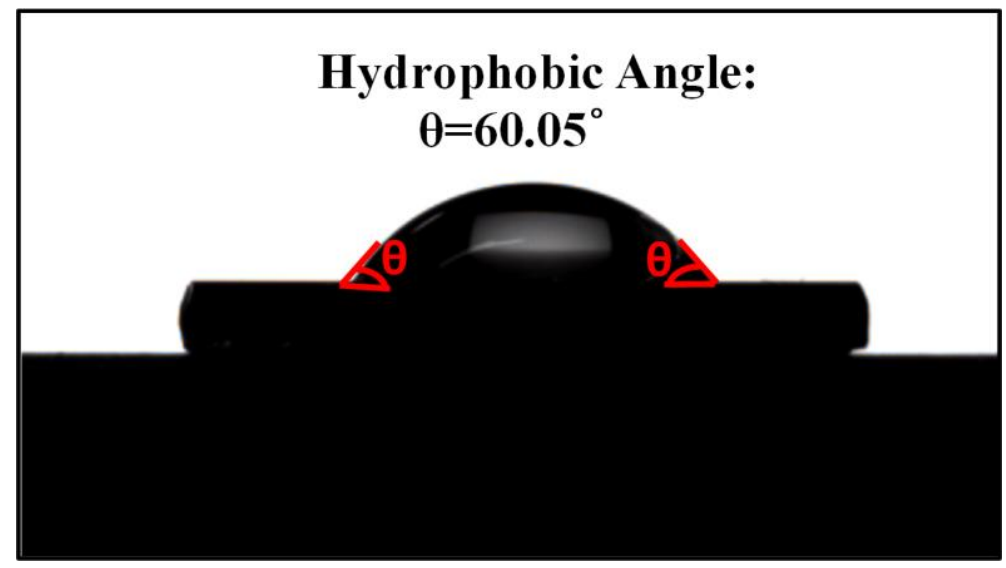

Figure S3. The detection results of hydrophobic angle for Si wafer after pre-treatments. 

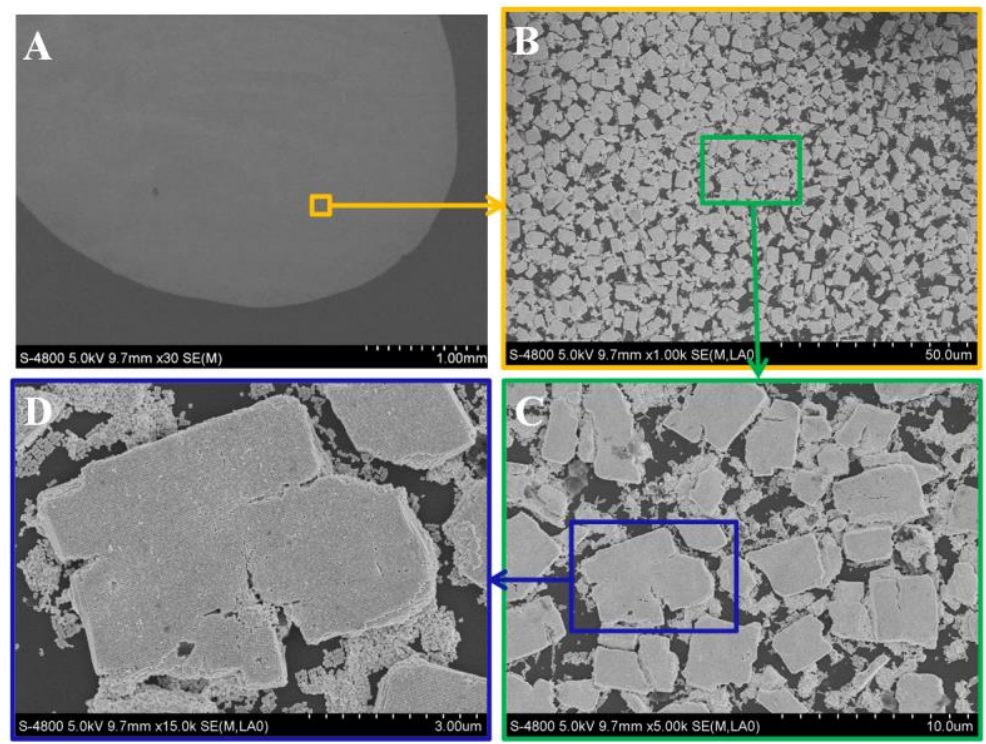

Figure S4. SEM images of the standing elongated rhombic dodecadedra superstructures with different magnifications.
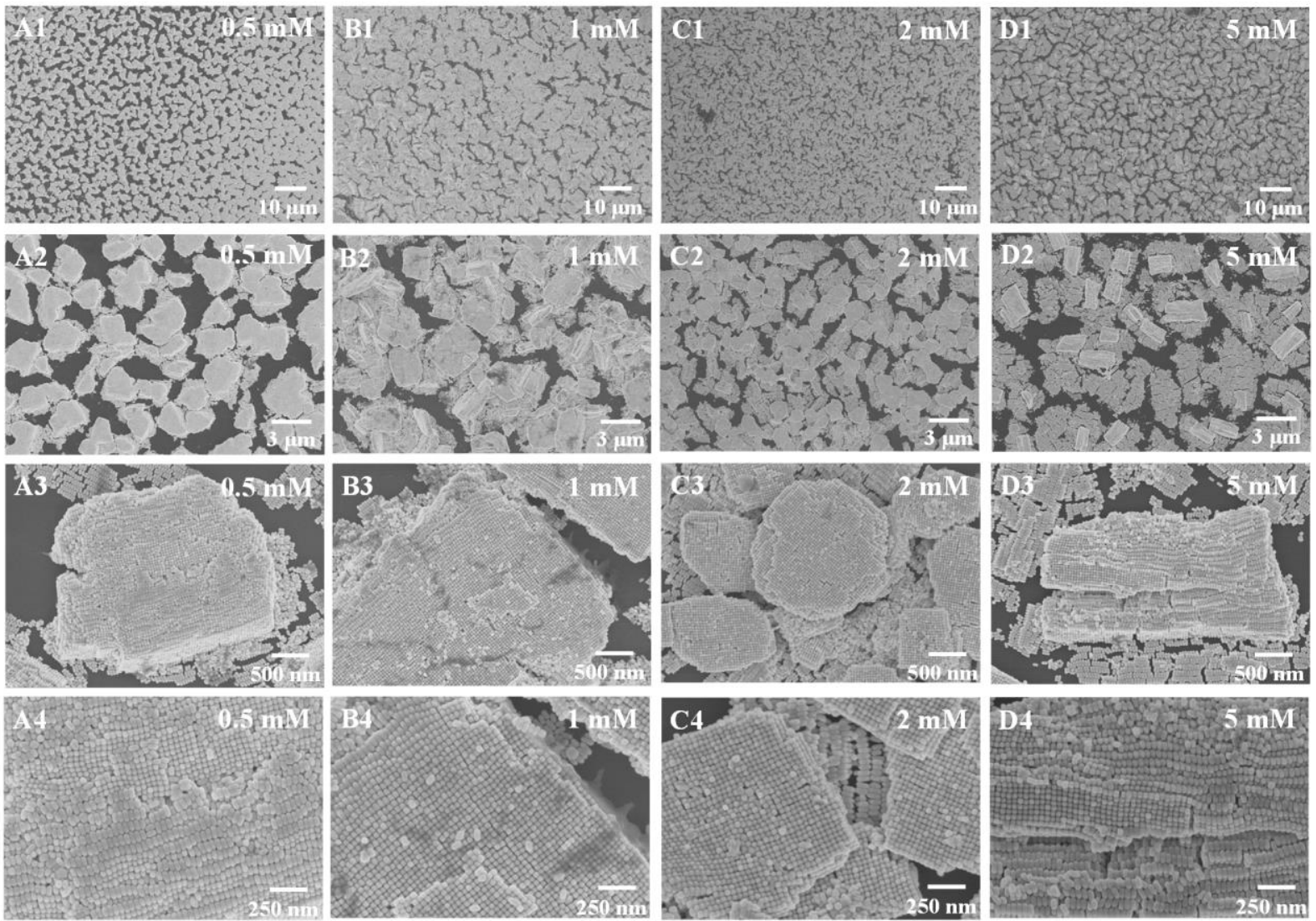

Figure S5. SEM images of the standing elongated rhombic dodecadedra superstructures with various concentrations of CTAC as surfactant (A1) (A4) $0.5 \mathrm{mM}$ (B1) (B4) $1 \mathrm{mM}$; (C1) (C4) $2 \mathrm{mM}$; (D1) (D2) $5 \mathrm{mM}$ at different magnification times (A1) (D1) 1K; (B1) (B4) 10 K; (C1) (C4) $30 \mathrm{~K}$; (D1) (D4) $60 \mathrm{~K}$. 

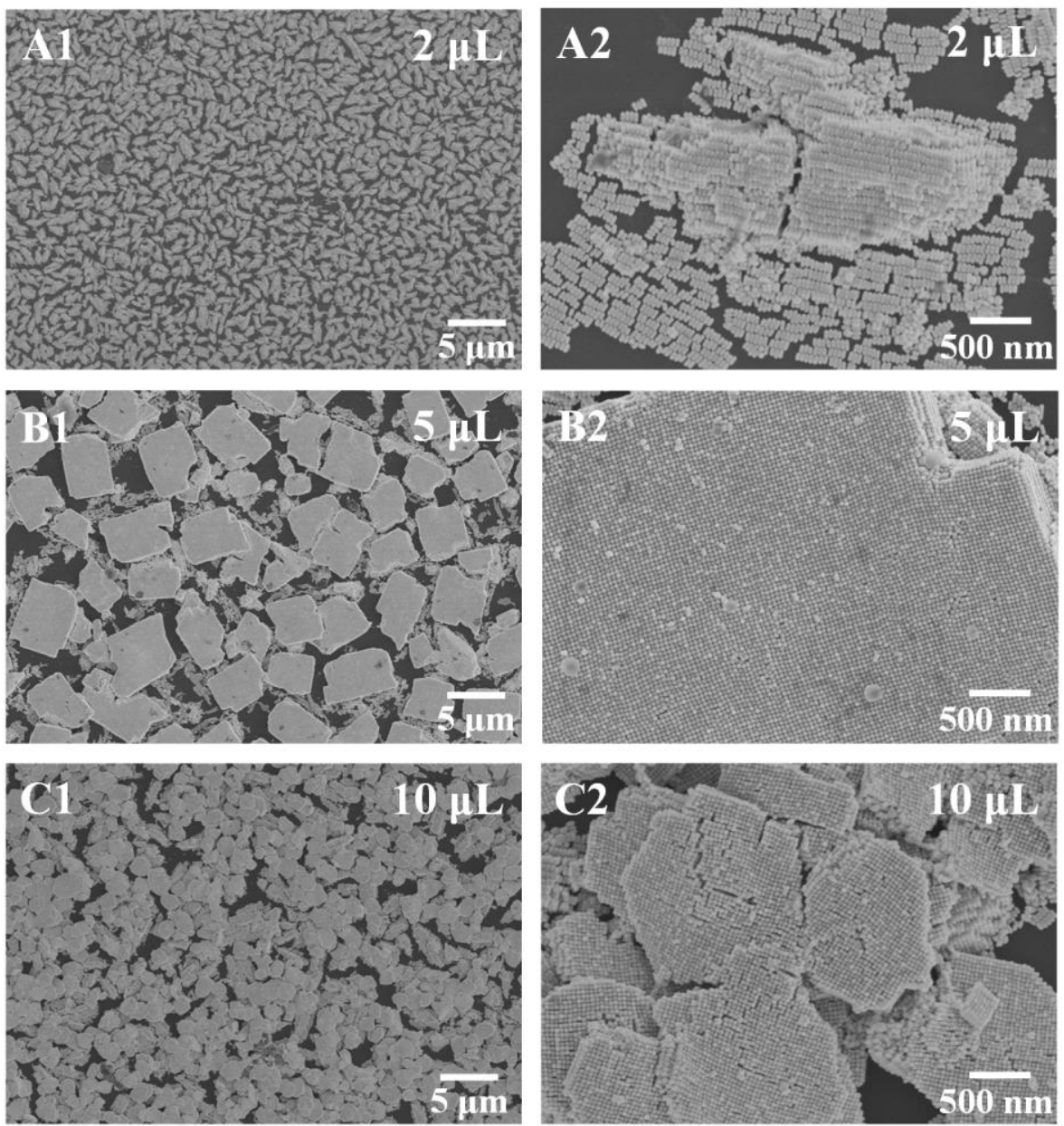

Figure S6. SEM images of the elongated rhombic dodecadedra superstructures with various amount of droplet (A1) (A2) $2 \mu \mathrm{L} ;$ (B1) (B2) $5 \mu \mathrm{L}$; (C1) (C2) 10 $\mu \mathrm{L}$ at different magnification times (A1) (C1) $5 \mathrm{~K}$; (A2) (C2) $30 \mathrm{~K}$.
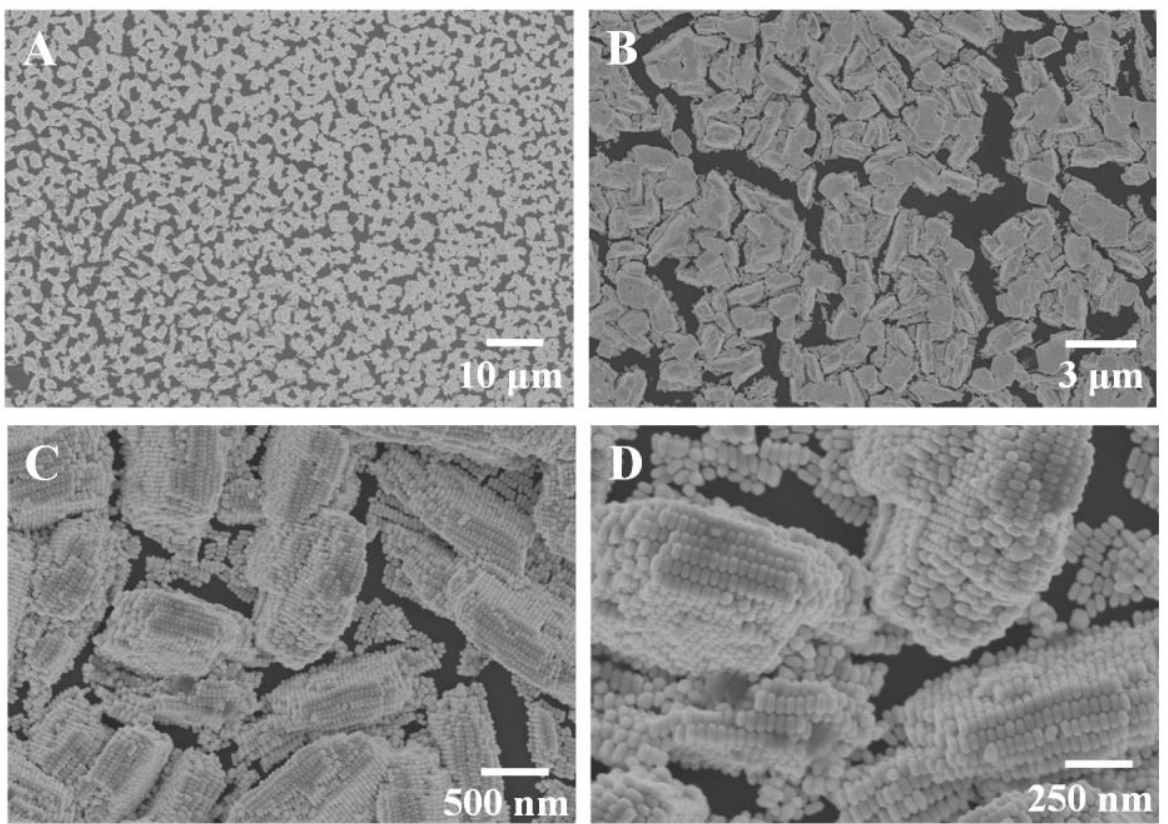

Figure S7. SEM images of the elongated rhombic dodecadedra superstructures assembled into horizontal arrangement at different magnification times (A) $1 \mathrm{~K}$; (B) $10 \mathrm{~K}$; (C) $30 \mathrm{~K}$; (D) $60 \mathrm{~K}$. 

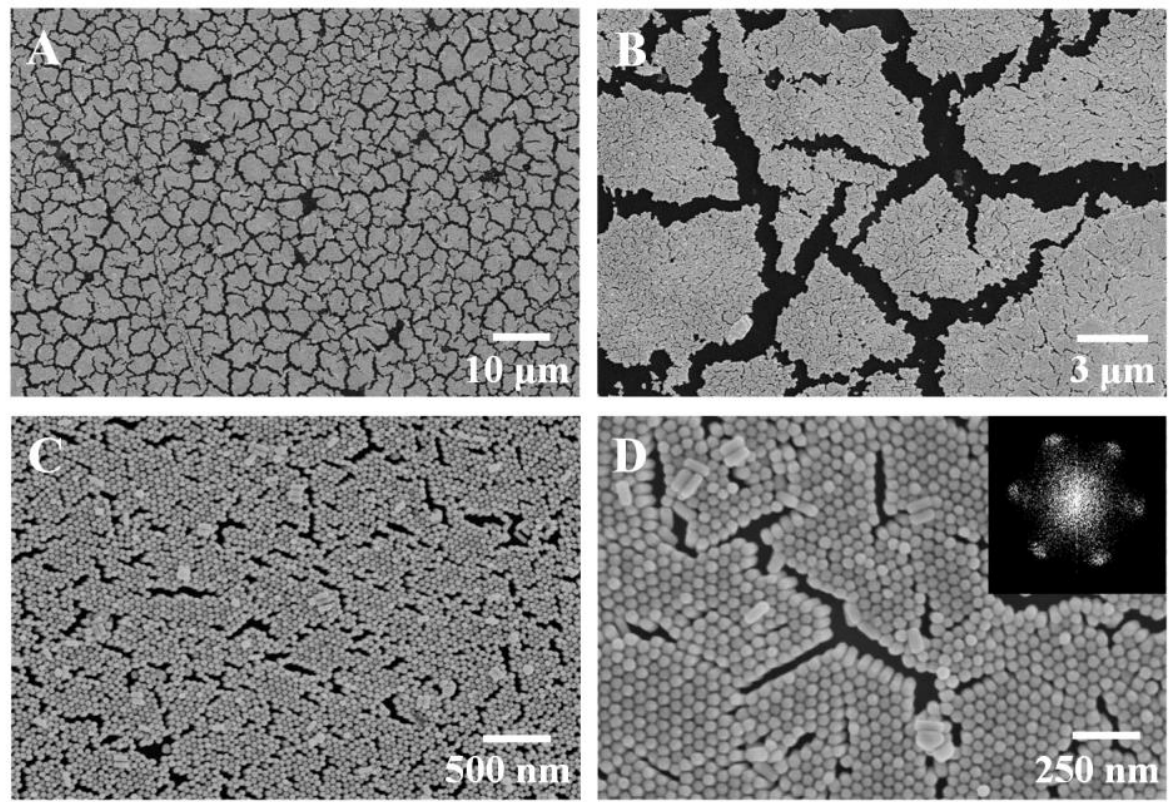

Figure S8. SEM images of the standing gold nanorod monolayer film at different magnification times (A) $1 \mathrm{~K}$; (B) $10 \mathrm{~K}$; (C) $30 \mathrm{~K}$; (D) $60 \mathrm{~K}$. Inset: FFT image of standing gold nanorod monolayer film.
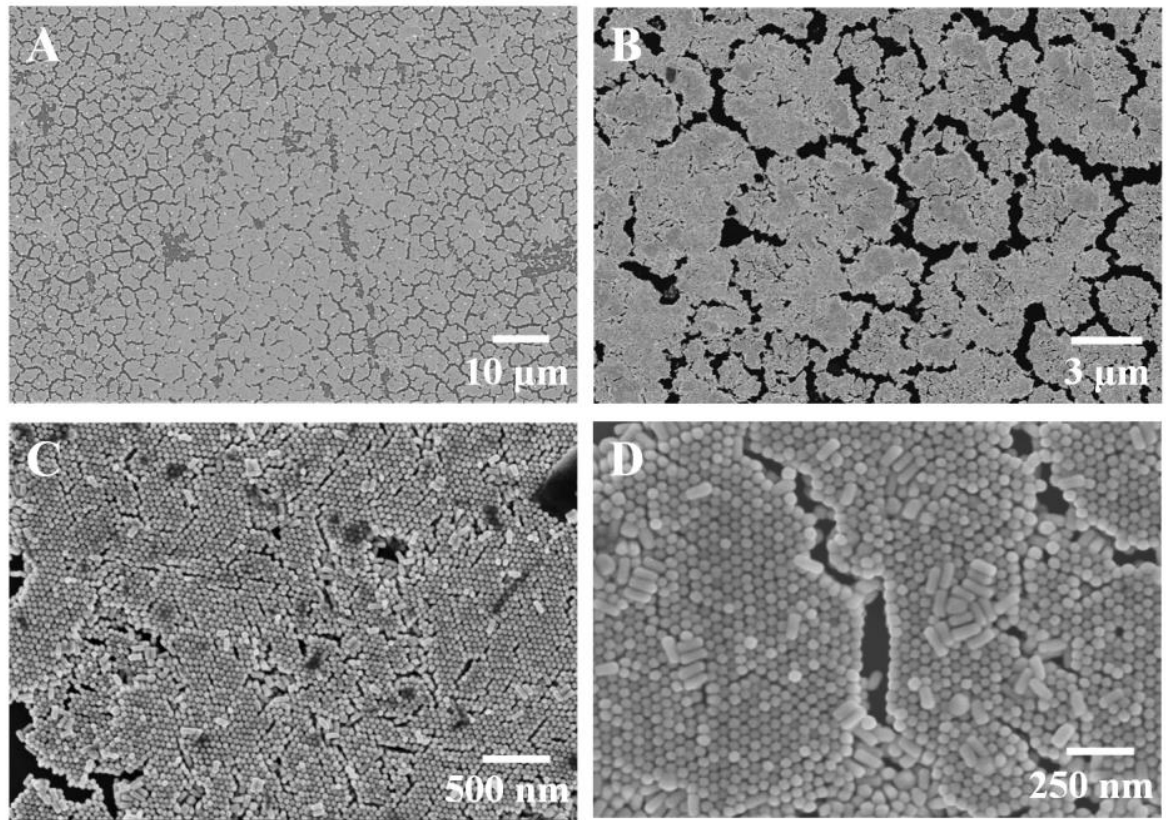

Figure S9. SEM images of the standing gold nanorod multi-layer film at different magnification times (A) $1 \mathrm{~K}$; (B) $10 \mathrm{~K}$; (C) $30 \mathrm{~K}$; (D) $60 \mathrm{~K}$. Inset: FFT image of standing gold nanorod multi-layer film. 

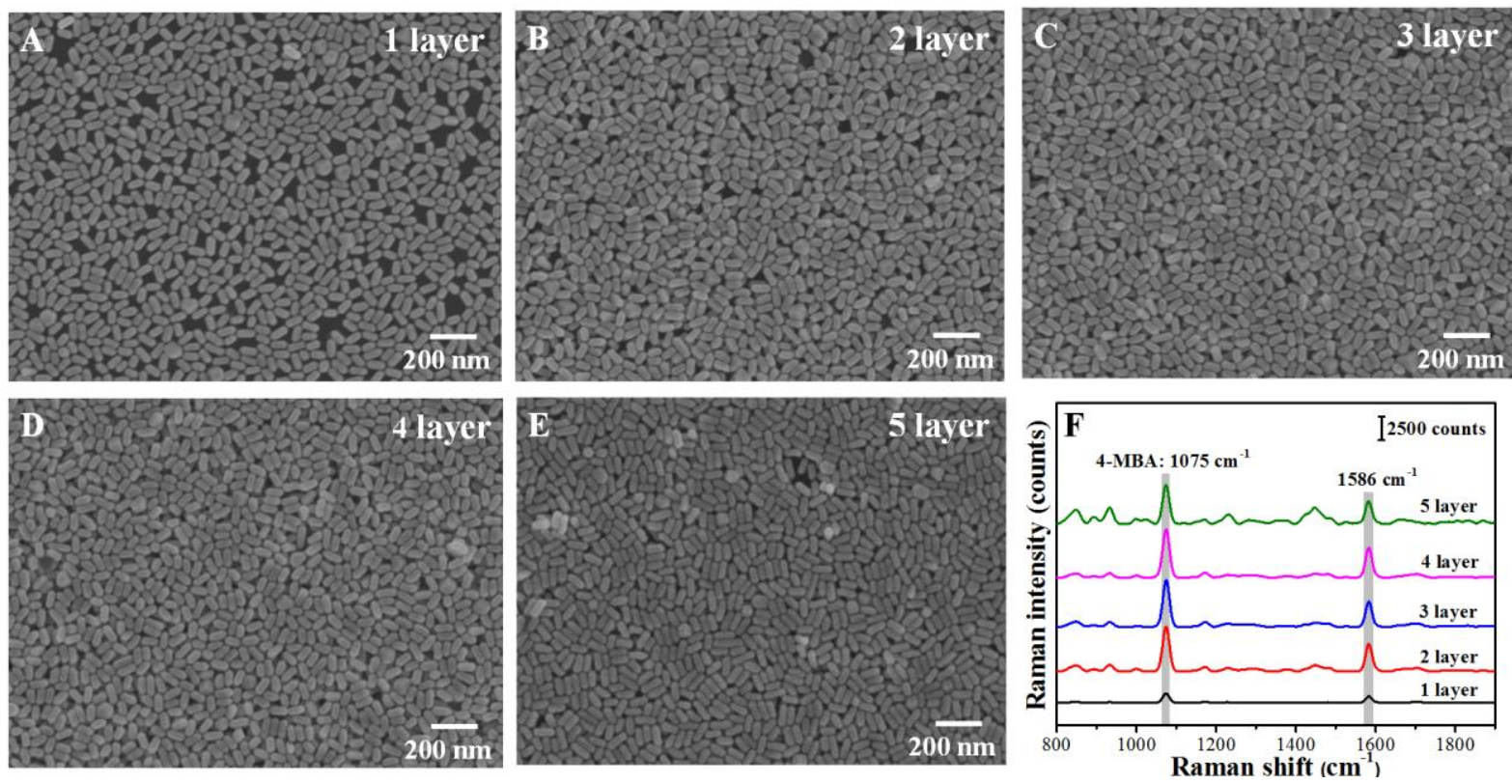

Figure S10. (A) (E) SEM images of the elongated rhombic dodecadedra array in a random arrangement with different layers by liquid/liquid self-assembly technique; (F) SERS spectra of 4-MBA molecule based on the elongated rhombic dodecadedra superstructures in a random arrangement with different layers.

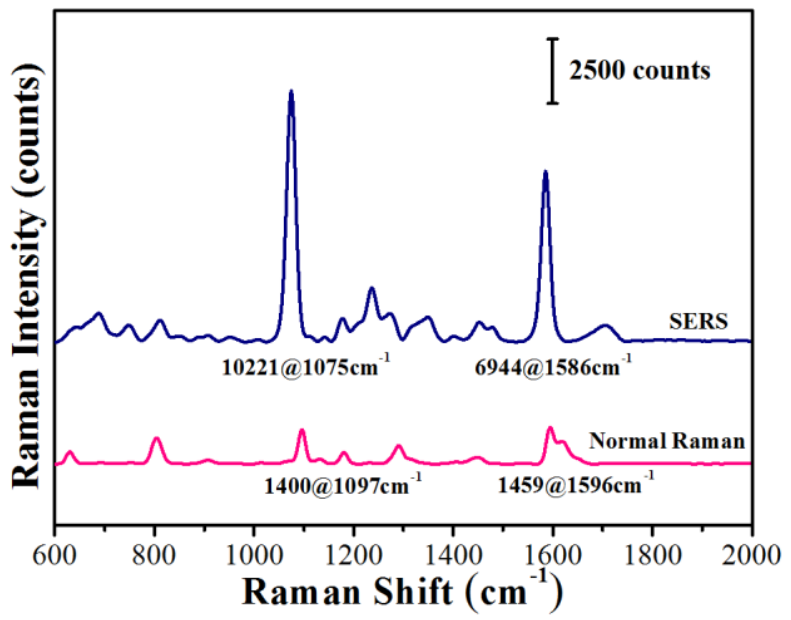

Figure S11. Normal Raman spectrum of 4-MBA solid powder and the SERS spectrum of $1 \mathrm{mM}$ 4-MBA ethanol solution, each spectrum represents the average value from five SERS spectra. 

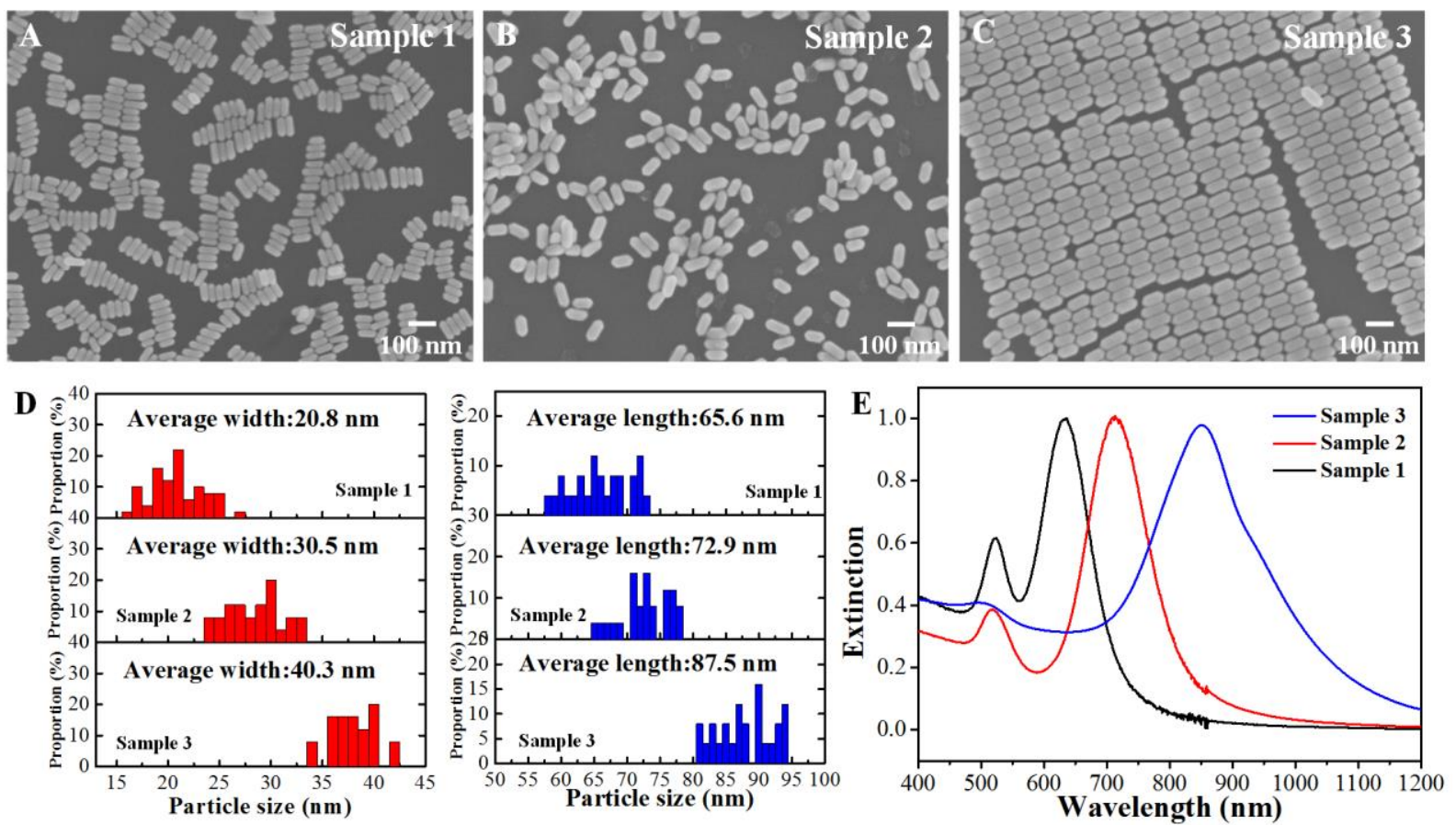

Figure S12. (A) (C) SEM images of elongated rhombic dodecadedra with three different width and length; (D) The statistical results of elongated rhombic dodecadedra with three different width and length; (F) Uv-vis absorption spectra of elongated rhombic dodecadedra with three different width and length.
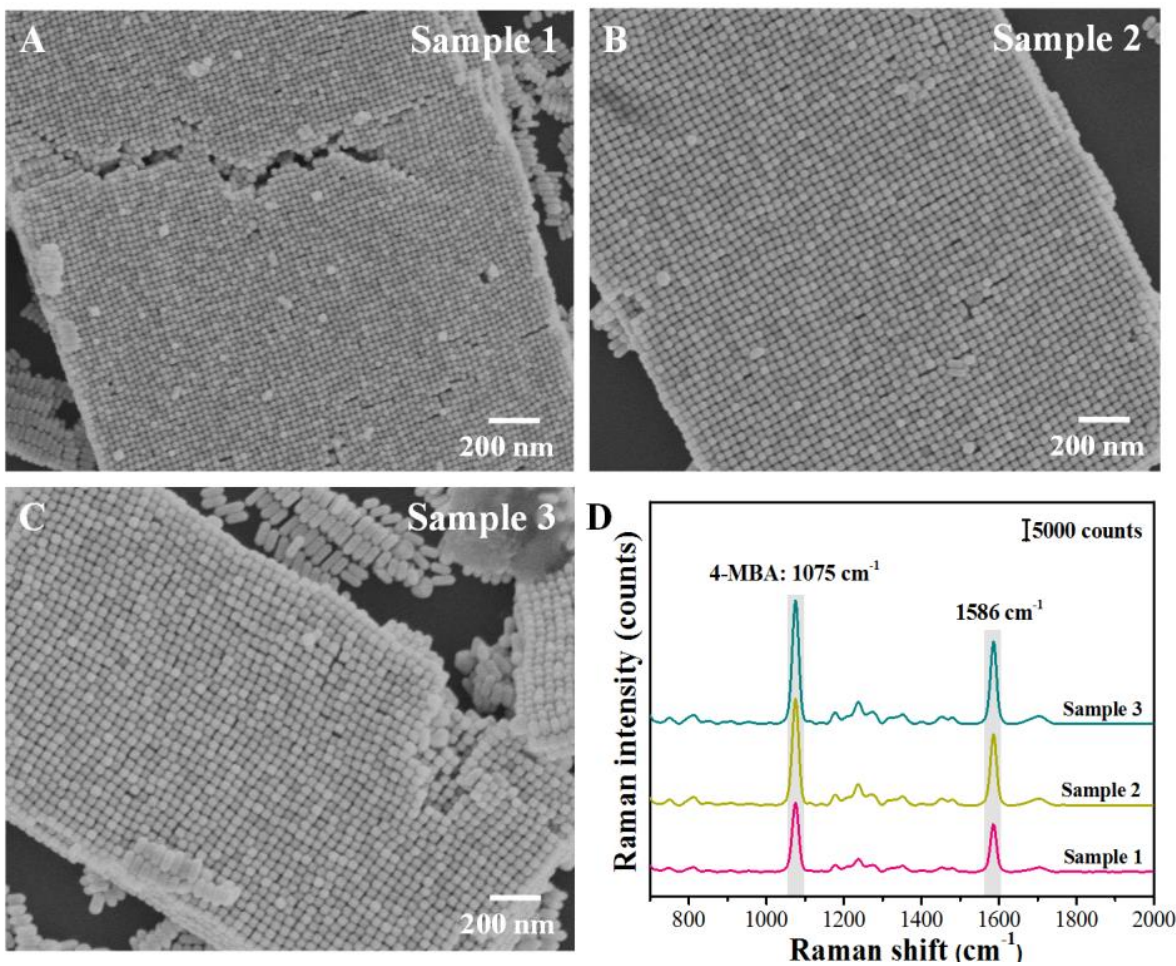

Figure S13. (A) (C) SEM images of the standing elongated rhombic dodecadedra superstructures with three different width and length; (D) SERS spectra of 4-MBA molecule based on the standing elongated rhombic dodecadedra superstructures with three different width and length. 
A
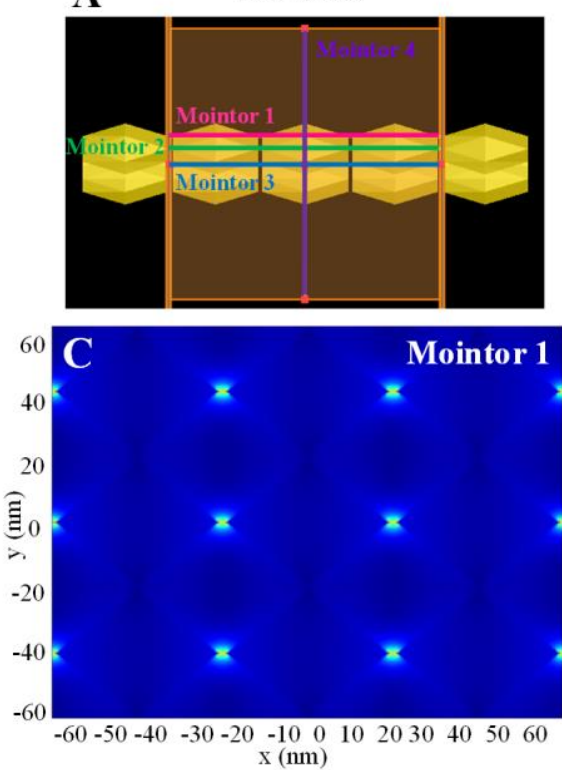

B Perspective view
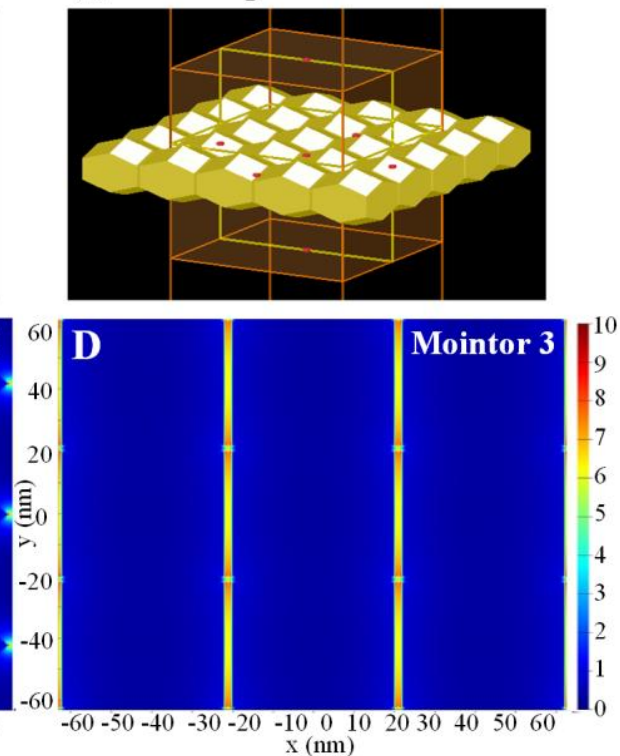

Figure S14. (A) FDTD simulation model of vertically aligned elongated rhombic dodecadedra periodic array in YZ view (A) and perspective view (B); The local electromagnetic field distribution in horizontal plane (x-y) (monitor 1 in (A)) (C) and vertical plane (x-z) (monitor 3 in (A)) (D).
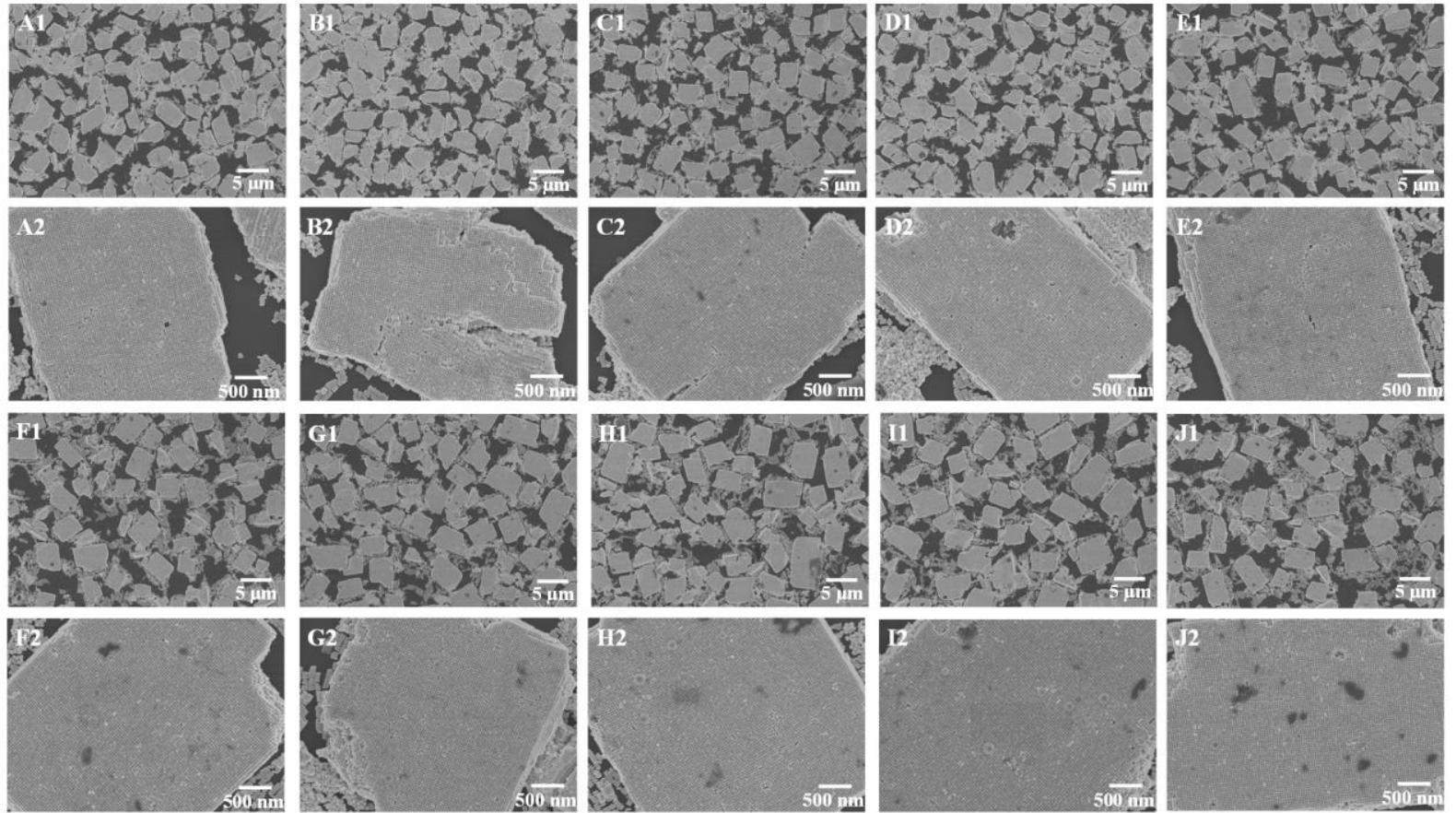

Figure S15. SEM images of the standing elongated rhombic dodecadedra superstructures fabricated from 10 different batches at different magnification times (A1) (J1) $5 \mathrm{~K} ;(\mathrm{A} 2) \sim(\mathrm{J} 2) 30 \mathrm{~K}$. 

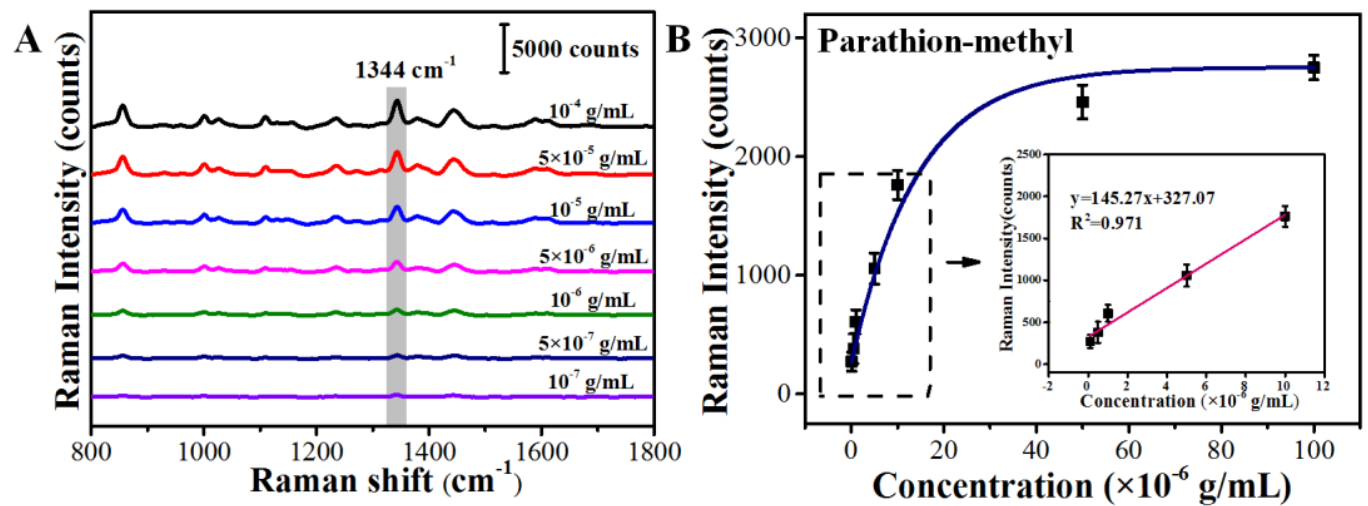

Figure S16. (A) The typical SERS spectra of gradient concentrations of parathion-methyl in water; (B) A function of the peak intensity at $1340 \mathrm{~cm}-1$ of parathion-methyl in water with the various concentrations. Inset: a linear fitting for peak intensity at $1344 \mathrm{~cm}^{-1}$ with the concentration ranging from $10^{-7} \mathrm{~g} / \mathrm{mL}$ to $10^{-5} \mathrm{~g} / \mathrm{mL}$.
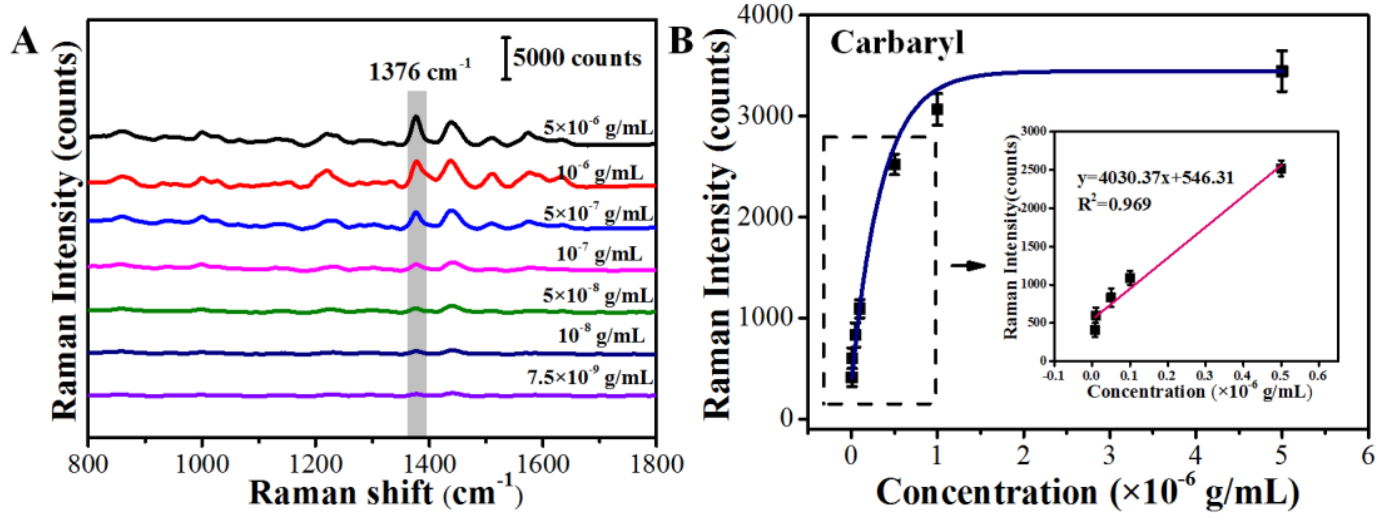

Figure S17. (A) The typical SERS spectra of gradient concentrations of carbaryl in water; (B) A function of the peak intensity at $1340 \mathrm{~cm}^{-1}$ of carbaryl in water with the various concentrations. Inset: a linear fitting for peak intensity at $1376 \mathrm{~cm}^{-1}$ with the concentration ranging from $7.5 \times 10^{-9} \mathrm{~g} / \mathrm{mL}$ to $5 \times 10^{-7} \mathrm{~g} / \mathrm{mL}$.

Table S1. Comparision of the detection for parathion-methyl with the previous work.

\begin{tabular}{cccc}
\hline Food matrix & LOD & Linear range & Reference \\
\hline Apple peel & $5 \times 10^{-7} \mathrm{~g} / \mathrm{g}$ & $5 \times 10^{-7} \sim 5 \times 10^{-5} \mathrm{~g} / \mathrm{g}$ & This work \\
Grape peel & $10^{-6} \mathrm{~g} / \mathrm{g}$ & $10^{-6} \sim 10^{-4} \mathrm{~g} / \mathrm{g}$ & \\
Water & $10^{-8} \mathrm{~mol} / \mathrm{L}$ & $10^{-8} \sim 10^{-6} \mathrm{~mol} / \mathrm{L}$ & {$[9]$} \\
Water & $10^{-7} \mathrm{~g} / \mathrm{L}$ & $10^{-7} \sim 10^{-1} \mathrm{~mol} / \mathrm{L}$ & {$[10]$} \\
Apple peel & $0.0008 \mathrm{mg} / \mathrm{kg}$ & ---- & {$[11]$} \\
\hline Table S2. Comparision of the detection for carbaryl with the previous work. \\
\hline Food matrix & LOD & Linear range & Reference \\
\hline Apple peel & $10^{-8} \mathrm{~g} / \mathrm{g}$ & $10^{-8} \sim 10^{-6} \mathrm{~g} / \mathrm{g}$ & This work \\
Grape peel & $10^{-7} \mathrm{~g} / \mathrm{g}$ & $10^{-7} \sim 10^{-5} \mathrm{~g} / \mathrm{g}$ & {$[12]$} \\
Water & $10^{-6} \mathrm{~g} / \mathrm{mL}$ & $10^{-3} \sim 10^{-6} \mathrm{~g} / \mathrm{mL}$ & {$[13]$} \\
Orange juice & $5 \times 10^{-8} \mathrm{~g} / \mathrm{mL}$ & $10^{-6} \sim 5 \times 10^{-8} \mathrm{~g} / \mathrm{mL}$ & {$[14]$} \\
Cucumber & $10^{-7} \mathrm{~mol} / \mathrm{L}$ & & ---- \\
Apple juice & $10^{-6} \mathrm{~g} / \mathrm{mL}$ & $3 \times 10^{-5} \sim 10^{-6} \mathrm{~g} / \mathrm{mL}$ & {$[15]$} \\
\hline
\end{tabular}




\section{REFERENCES}

[1] Ye, X.; Zheng, C.; Chen, J.; Gao, Y.; Murray, C. B. Using Binary Surfactant Mixtures to Simultaneously Improve the Dimensional Tunability and Monodispersity in the Seeded Growth of Gold Nanorods. Nano Lett. 2013, 13, 765-771.

[2] Laramy, C. R.; Lopez-Rios, H.; O’Brien, M. N.; Girard, M.; Stawicki, R. J.; Lee, B.; de La Cruz, M. O.; Mirkin, C. A. Controlled Symmetry Breaking in Colloidal Crystal Engineering with DNA. ACS Nano, 2018, 13, 1412-1420.

[3] Lin, X.; Fang, G.; Liu, Y.; He, Y.; Wang, L.; Dong, B. Marangoni Effect-Driven Transfer and Compression at Three-Phase Interfaces for Highly Reproducible Nanoparticle Monolayers. J Phys. Chem. Lett. 2020, 11, 3573-3581.

[4] Danilowicz, C.; Greenfield, D.; Prentiss, M. Dissociation of Ligand-Receptor Complexes Using Magnetic Tweezers. Anal. Chem. 2005, 77, 3023-3028.

[5] Tikku, S.; Dan, N. Amphiphile-induced stabilization of hydrophobic colloidal particles in aqueous solutions. Langmuir 2003, 19, 491-494.

[6] Orendorff, C. J.; Gole, A.; Sau, T. K.; Murphy, C. J. Surface-Enhanced Raman Spectroscopy of Self-Assembled Monolayers: Sandwich Architecture and Nanoparticle Shape Dependence. Anal. Chem. 2005, 77, 3261-3266.

[7] Janiga, I.; Mocak, J.; Garaj, I. Comparison of Minimum Detectable Concentration with the IUPAC Detection Limit. Meas. Sci. Rev. 2008, 8, 108-110.

[8] Mocák, J.; Janiga, I.; Rábarová, E. Evaluation of IUPAC Limit of Detection and Iso Minimum Detectable Value Electrochemical Determination of Lead. Nova Biotechnologica 2009, 9, 91-100.

[9] Huang, D.; Zhao, J.; Wang, M.; Zhu, S. Snowflake-Like Gold Nanoparticles as SERS Substrates for the Sensitive Detection of Organophosphorus Pesticide Residues. Food Control 2020, 108, No. 106835.

[10] Yaseen, T.; Pu, H.; Sun, D. W. Rapid Detection of Multiple Organophosphorus Pesticides (Triazophos and Parathion-Methyl) Residues in Peach by SERS based on Core-Shell Bimetallic Au@Ag NPs. Food Addit. Contam. A 2019, 36, 762-778.

[11] Luo, W.; Chen, M.; Hao, N.; Huang, X.; Zhao, X.; Zhu, Y.; Yang, H.; Chen, X. In Situ Synthesis of Gold Nanoparticles on Pseudo-Paper Films as Flexible SERS Substrate for Sensitive Detection of Surface Organic Residues. Talanta, 2019, 197, 225-233.

[12] Zhang, X.; Niu, C.; Wang, Y.; Zhou, S.; Liu, J. Gel-Limited Synthesis of Dumbbell-Like $\mathrm{Fe}_{3} \mathrm{O}_{4}-\mathrm{Ag}$ Composite Microspheres and their SERS Applications. Nanoscale, 2014, 6, 12618-12625.

[13] Alsammarraie, F. K.; Lin, M. Using Standing Gold Nanorod Arrays as Surface-Enhanced Raman Spectroscopy (SERS) Substrates for Detection of Carbaryl Residues in Fruit Juice and Milk. J Agr. Food Chem. 2017, 65, 666-674.

[14] Cheng, D.; Bai, X.; He, M.; Wu, J.; Yang, H.; Ran, J.; Cai, G.; Wang, X. Polydopamine-Assisted Immobilization of Ag@Au NPs on Cotton Fabrics for Sensitive and Responsive SERS Detection. Cellulose 2019, 26, 4191-4204.

[15] Fan, Y.; Lai, K.; Rasco, B. A.; Huang, Y. Determination of Carbaryl Pesticide in Fuji Apples Using Surface-Enhanced Raman Spectroscopy Coupled with Multivariate Analysis. LWT-Food Sci.Technol. 2015, 60, 352-357. 